\title{
Headache and anxiety/mood disorders: are we trapped in a cul-de-sac?
}

Federica Galli ${ }^{*}$ (D)

Keywords: Migraine, Headache, Anxiety, Depression, Psychiatric comorbidity

After the nth papers on the relationship between migraine and depression [1-3], I think it is the time to open a debate on the meaning of making research on the comorbidity of headache, anxiety and depression. It was 1990, when K. Merikangas published the first pioneering paper on the relationship of migraine, anxiety and depression, outlining the existence of a comorbid association with a bidirectional influence from one disorder to the other(s) and advancing several hypotheses to explain such a comorbidity. Conclusions after 26 years of research on the issue remain the same [1], with the additional complication that comorbid anxiety and depression seems not to be a prerogative of migraine, but of all kind of chronic headache (more frequent and severe are headache attacks more probable the presence of comorbid anxiety and depression-worse is the clinical situation of headache higher the probability of comorbid anxiety and depression). I think the time is mature to admit that we are in a cul-de-sac, and we need a way out. If we look to the literature on the issue anxiety/ depression and pain other than headache (neck, back, abdominal, musculoskeletal pain, and so on), we will find the same strong comorbid association. Even in rarer clinical disorders (e.g. Burning Mouth Syndrome), we found that anxiety and depression are the most represented comorbid disorders [4]. To complicate the scene, if we look to other common or uncommon, severe or not severe non-painful disorders or diseases (e.g. hearth failure, chronic kidney disease, chronic obstructive pulmonary disease, gastritis and so on) we find again the same strong comorbid association (and I do not open the door on the comorbidity of anxiety and mood disorders with other psychiatric disorders). So, it is the time to advance some consideration on the matter, because the bias of considering anxiety/depression as specifically related to headache (and not strongly related to many different medical conditions as well) constrained us in a no way out. Fruitful lines of research are related to aspects that might help in explaining anxiety and depression components of headache, as personality characteristics, child trauma, abnormal illness behavior, recent life-events, allostatic load (the failure of an organism to achieve stability through change), and so on. New insights could be gained crossing clinical psychological factors with data from imaging studies.

A final warning on the use of the Hospital Anxiety and Depression Scale (HADS) to assess psychiatric comorbidity $[2,3]$, because we risk misapplication and misinterpretation of findings. The HADS is a useful screening test for detecting symptoms of anxiety and depression one week before a probable hospitalization. Symptoms do not mean diagnoses, which need ad hoc structured questionnaire and/or clinical interview. Any conclusion based on the HADS is at best speculative, because it does not allow a clear-cut diagnosis of "anxiety" and/or "depression".

\footnotetext{
* Correspondence: federica.galli1@unimi.it

Department of Health Sciences-University of Milan, Via A. di Rudinì, 8, 20147 Milan, Italy
} 
Finally, I suggest the involvement of clinical psychologists and clinical researchers in planning and realizing research on psychological components of headache, because the number of suitable instruments to detect the psychological characteristics of patients is very wide, changes with age and depends on the psychological constructs one chooses to analyse. I do not know if it will drive us out of the sac, but it will unquestionably help!

\section{Authors' response}

Timothy J. Steiner ${ }^{1,2}$, Christian Lampl ${ }^{3}$, Mattias Linde ${ }^{1}$, Christian Wöber ${ }^{4}$ and Karin Zebenholzer ${ }^{4}$

${ }^{1}$ Norwegian University of Science and Technology (NTNU), Trondheim, Norway

${ }^{2}$ Imperial College London, London, UK

${ }^{3}$ Headache Medical Center, Linz, Austria

${ }^{4}$ Universitätsklinik für Neurologie, Medizinische Universität Wien, Vienna, Austria

Dr Galli has a point. It is both depressing and anxietyinducing to be in a cul-de-sac with no apparent way out. Her suggestion to involve clinical psychologists and clinical researchers in planning and realizing research on psychological components of headache is sensible. Sadly, it does not point to a way out, since she offers no further suggestion on what form that research might take to succeed in this purpose.

Meanwhile, perhaps Dr Galli also misses a point. Regardless of specificity to headache versus other pain or chronic disorders (which is not claimed), these associations assessed in the context of population-based studies are highly relevant to needs assessments, formulation of health policy, the structure of health-care provision and resource allocation to it. These studies generally recognise that HADS [5] is not a diagnostic instrument, but its long and respected history of application in epidemiological studies does not support her contention that "Any conclusion based on the HADS is at best speculative".

\section{Competing interests}

The author declares that she has no competing interests.

Received: 1 November 2016 Accepted: 8 December 2016

Published online: 13 January 2017

\section{References}

1. Risal A, Manandhar K, Holen A, Steiner TJ, Linde M (2016) Comorbidities of psychiatric and headache disorders in Nepal: implications from a nationwide population-based study. J Headache Pain 17:45

2. Zebenholzer K, Lechner A, Broessner G, Lampl C, Luthringshausen G, Wuschitz A, Obmann SM, Berek K, Wöber C (2016) Impact of depression and anxiety on burden and management of episodic and chronic headaches - a cross-sectional multicentre study in eight Austrian headache centres. J Headache Pain 17(1):15, 1-10

3. Lampl C, Thomas H, Tassorelli C, Katsarava Z, Laínez JM, Lantéri-Minet M, Rastenyte D, Ruiz de la Torre E, Stovner LJ, Andrée C, Steiner TJ (2016) Headache, depression and anxiety: associations in the Eurolight project. $J$ Headache Pain 17(1):59

4. Galli F, Lodi G, Sardella A, Vegni E (2016) The role of psychological factors in burning mouth syndrome: a systematic review and meta-analysis. Cephalalgia [Epub ahead of print]

5. Zigmond AS, Snaith RP (1983) The hospital anxiety and depression scale. Acta Psychiatr Scand 67(6):361-370. doi:10.1111/j.1600-0447.1983.tb09716.x. PMID6880820

\section{Submit your manuscript to a SpringerOpen ${ }^{\circ}$ journal and benefit from:}

- Convenient online submission

- Rigorous peer review

- Immediate publication on acceptance

- Open access: articles freely available online

- High visibility within the field

- Retaining the copyright to your article

Submit your next manuscript at springeropen.com 